\title{
DETERMINATION OF THE POTENTIAL OF KAMIAS (AVERRHOA BILIMBI) FLOWERS FOR TEA DEVELOPMENT
}

\author{
Baby Richard R. Navarro', Jessamine Beatriz P. Oña ${ }^{2}$ \\ ${ }^{1}$ Institute of Food Science and Technogy, College of Agriculture and Food Science, University of the Philippines \\ Banos, College, Laguna 4031, Philippines \\ ${ }^{2} 2108$ Prosperity Avenue, Carmelray Industrial Park 1, Carmeltown,Canlubang, Calamba, Laguna.
}

\begin{abstract}
Three methods of drying, namely: sun drying, freeze drying, and cabinet drying, were applied to Kamias leaves (Averrhoa bilimbi), a traditional herbal medicine.The leaves were then made into tea and its acceptability was tested through sensory evaluation. Several tests were also applied to determine the potential of kamiasas a tea. These tests include phenolic content determination, radical scavenging activity determination, and reducing power assay. After the evaluation of sensory attributes of kamias flower teas from three drying methods, the sun-dried kamias flower tea received the highest score in all attributes compared to the cabinet- and freeze-dried kamias flower teas. The sun-dried kamiasflower tea was compared with rose flower tea based on their sensory properties and antioxidant activities. For the sensory evaluation, the results showed that kamias flower teamay have had weaker aroma than rose, but their general acceptability attribute had equal scores. Chemical analyses for antioxidant activity such as DPPH radical scavenging activities, total phenolic and flavonoid contents determination, and reducing power assay, were conducted on sun-dried kamias and rose flower teas. Kamias flower tea had higher phenolic and flavonoid contents and stronger reducing power compared to rose flower tea, but rose flower tea had higher radical scavenging activity than kamias flower. This suggested that kamiasflower tea had more reducing than scavenging antioxidants. Nevertheless, both flowers were found to have antioxidant activities.The results from sensory evaluation and chemical analyses proved that kamias flowers can be used in flower tea development since it contained antioxidants and was equally acceptable as rose flower tea.
\end{abstract}

Keywords: Flower tea, Tea, Herbal medicine and Kamias

\section{INTRODUCTION}

According to the World Health Statistics released by the World Health Organization (2015), the life expectancies at birth of Filipinos in 2013 are 65 for male and 72 for female, compared with the 1990 records, 63 and 70, respectively. However, statistics also showed that, for every 100,000 Filipinos, the mortality rates were 227 from communicable diseases and 720 from non-communicable diseases (NCDs). NCDs are not contagious but can greatly affect a person's life, and, if not given proper attention, they can lead to death. According to the Department of Health, of the top causes of mortality in the Philippines, four are NCDs, namely, cardiovascular diseases, cancers, diabetes mellitus, and chronic obstructive pulmonary disease. These diseases, generally, can be traced from unhealthy diet and poor lifestyle.

To cure NCDs, aside from taking prescription drugs, some Filipinos also take herbal medicines or drinks. Knowing that the demand is slowly shifting to organic and natural products, there is now an increasing number of products of plant origin, such as tea and other herbal infusions. Originally, tea was discovered in China when some leaves of Camellia sinensisfell in a pot of hot water. Tea is a rich source of methylxanthines, volatile compounds, and polyphenolic compounds that are believed to prevent cancer and some cardiovascular diseases [1]. However, over time, people have discovered other plant sources and used other plant parts that can serve as infusions or decoctions. One of the traditional herbal medicines is kamias (Averrhoa bilimbi). However, this plant, especially its fruits, is underutilized despite its medical and culinary uses. Kamias leaves can be made into an infusion as a tonic or into paste applied to cure itches, mumps, and rheumatism. Its infusion is also believed to cure cough and thrush. Also, with its high oxalic acid content, kamias fruit is used as a stain remover. Moreover, it has anti-diabetic and anti-hyperlipidaemic activities, as well as antimicrobial property [2], [3].

The main objective of this study is to determine the potential of kamias as flower tea. The specific objectives are as follows: (1) to identify which drying method will yield the most acceptablekamiasflower tea through sensory evaluation, (2) to compare the sensory properties of kamias and conventional rose flower teas through sensory evaluation; and (3) to determine its antioxidant activities and compare them with the antioxidant activities of rose flower tea.

\section{MATERIALS AND METHODS}

\subsection{Time and Place of Study}

The sensory evaluations and chemical analyses were done at the Institute of Food Science and Technology, UPLB, on October 2016 to April 2017. 


\subsection{Raw Materials}

Mature kamias flowers were picked by hand at 6 to 10 am from San Roque, Sto. Tomas, Batangas and from the garden of Post-Harvest Institute, UPLB. The kamias trees were chosen because of their being distant from the major roads to ensure minimum absorption of emissions from vehicles.

\subsection{Drying}

For sun drying, kamias flowers were laid in a clean, stainless tray, covered with metal screen wire and were placed under direct sunlight from morning until afternoon (9 h). Freeze drying was done by pre-freezing the kamias flowers before it was brought to Crop Protection Cluster at the Institute of Biological Sciences, UPLB. The frozen flowers were placed in paper bag poked with holes before it was subjected to freeze drying to facilitate sublimation of water molecules. The process started at 8:00 am and ended at 4:30 pm. Lastly, cabinet drying was done in the Pilot Plant of the Institute of Food Science and Technology. The flowers in trays and placed in the dryer set at $40^{\circ} \mathrm{C}$ for 13 hours. The dried flowers from each drying method were then separately placed in glass jars and stored at cool temperature.

\subsection{Sensory Evaluation}

Flower teas from different drying methods were evaluated by 25 tea drinkers by quality scoring. To avoid biases, each sample was assigned with random code numbers. The judges rated each tea based on their color, aroma, flavor, aftertaste, and general acceptability. The flower tea sample from the drying method with the highest general acceptability was compared with a commercial rose flower tea, based on their sensory evaluation and antioxidant activities. The aroma, flavor, aftertaste, and general acceptability of kamias and rose flower teas were evaluated by 25 tea drinkers using quality scoring.

\subsection{Total Phenolic and Flavonoid Determination}

The total phenolic and flavonoid content determination was done using Folin-Ciocalteu assay based on [4]. $0.20 \mathrm{~mL}$ of the sample was added with $0.5 \mathrm{~mL}$ of $50 \%$ Folin-Ciocalteu reagent and $3 \mathrm{~mL}$ of $10 \%$ sodium carbonate. It was stood for 10 minutes and added with $10 \mathrm{~mL}$ of distilled water. The mixture was subjected to a vortex mixer before its absorbance was read in a spectrometer set at $700 \mathrm{~nm}$. Gallic acid was used as the reference for plotting the standard curve. Linear regression was used to determine the concentration of the sample, which will be used to compute for the Gallic Acid Equivalent (GAE) and Quercetin Equivalent for flavonoid, using the formula:

$$
\begin{aligned}
& \mathrm{GAE}=\frac{\text { Concentration from Standard Curve } * \text { Volume of sample }}{\text { Mass of dry material used }} \\
& \mathrm{QE}=\frac{\text { Concentration from Standard Curve } * \text { Volume of sample }}{\text { Mass of dry material used }}
\end{aligned}
$$

\subsection{DPPH Radical Scavenging Activity Assay}

The DPPH radical scavenging activity assay used was based on the procedure of [5]. The kamiasand rose flower teas were prepared by separately steeping the flowers in freshly boiled water for 2 minutes. Then, $1 \mathrm{mM}$ of DPPH was freshly prepared. In a covered tube, one $\mathrm{mL}$ of each sample was added with $4 \mathrm{~mL}$ of water and $1 \mathrm{~mL}$ of DPPH solution. It was stood for 30 minutes in a dark room. A blank was also made. The absorbance of each sample was read using a spectrometer set at $517 \mathrm{~nm}$. The following formula was used:

\section{\%DPPH scavenging activity $=\left(1-\frac{\text { sample absorbance }}{\text { blank absorbance }}\right) * 100$}

\subsection{Reducing Power Assay}

The reducing power assay was performed using the method of [6]. $0.1 \mathrm{~mL}$ of samples were added with $0.5 \mathrm{~mL}$ distilled water, $1.5 \mathrm{~mL}$ phosphate buffer and $1.5 \mathrm{~mL}$ potassium ferricyanide. It was then put in a water bath $\left(50^{\circ} \mathrm{C}\right)$ for 20 minutes, and added with $2.5 \mathrm{~mL}$ of $10 \%$ trichloroacetic acid. The tubes were then centrifuged at $3000 \mathrm{rpm}$ for $10 \mathrm{~min}$, and $0.5 \mathrm{~mL}$ of supernatant was taken and transferred to another tube. Supernatant was then added with $1.5 \mathrm{~mL}$ distilled water and $0.3 \mathrm{~mL}$ of ferric chloride. The absorbance was then read at $700 \mathrm{~nm}$ using a spectrometer. The \% reducing power was calculated by using the formula:

$$
\% \text { Reducing Power }=\left(\frac{\text { Absorbance }_{\text {gample }}}{\text { Absorbance }_{\text {blank }}}-1\right) * 100
$$

\subsection{Statistical Analysis}

To determine if there are significant differences in the sensory attributes between the kamiasflower tea from three drying methods, and between the most acceptable kamias flower tea and rose flower tea, Analysis of Variance (ANOVA) in Randomized Complete Block Design, and Tukey's Honest Significant Difference test (when a minimum difference was observed) were employed using Statistical Tool for Agricultural Research (STAR) software. While, for the antioxidant activity analyses, one-sample Ttest was used to determine if the kamias flower tea is significantly different from rose flower tea.

\section{RESULTS AND DISCUSSION}

\subsection{Sensory Evaluation}

\subsubsection{Sensory Evaluation among Three Drying}

\section{Methods}

After 25 judges had evaluated kamias flower tea prepared by three drying methods, the scores were encoded and analyzed with Statistical Tool for Agricultural Research (STAR) software using randomized complete block design (RCBD). The results, as shown in Table 2, showed that there were no significant differences among the attributes of the three samples except for their flavor attribute. 
Table 2: Results of ANOVA for the attributes of kamias flower tea from three drying methods.

\begin{tabular}{|l|l|l|l|}
\hline Attribute & F-value & $\operatorname{Pr}(>$ F) & \\
\hline Color & 3.15 & 0.0519 & $\mathrm{~ns}$ \\
\hline Aroma & 0.22 & 0.8020 & $\mathrm{~ns}$ \\
\hline Flavor & 4.95 & 0.0111 & $\mathrm{~s}$ \\
\hline Aftertaste & 2.00 & 0.1462 & $\mathrm{~ns}$ \\
\hline $\begin{array}{l}\text { General } \\
\text { Acceptability }\end{array}$ & 0.84 & 0.4366 & $\mathrm{~ns}$ \\
\hline *ns= not significantly different; s= significantly different \\
\hline
\end{tabular}

With the significant difference detected in the flavor attribute, Tukey's Honest Significant Difference (HSD) Test was employed to assess this difference. As shown in Table 3 , samples with same letter show no significant difference between them. Thus, the flavor of freeze-dried kamias flower tea is not significantly different from those of the other samples. However, those of the cabinet- and sun-dried kamias flower teas are statistically different from each other.

Table 3: Tukey's HSD test on the flavor of kamias flower

\begin{tabular}{|l|l|l|l|l|l|}
\hline Drying & $\begin{array}{l}\text { Mean } \\
\text { Method }\end{array}$ & $\begin{array}{l}\text { Error } \\
\text { Mean } \\
\text { Square }\end{array}$ & $\begin{array}{l}\text { Critica } \\
1 \\
\text { Value }\end{array}$ & $\begin{array}{l}\text { Test } \\
\text { Statistic }\end{array}$ & $\begin{array}{l}\text { HS } \\
\mathrm{D}\end{array}$ \\
\hline $\begin{array}{l}\text { Cabinet } \\
\text { drying }\end{array}$ & 2.92 & 1.7039 & 3.4203 & 0.8929 & $\mathrm{~b}$ \\
\cline { 1 - 2 } $\begin{array}{l}\text { Freeze- } \\
\text { drying }\end{array}$ & 3.56 & & & $\mathrm{ab}$ \\
\hline Sun drying & 4.08 & & & $\mathrm{a}$ \\
\hline $\begin{array}{l}\text { *Samples with the same letter are not significantly } \\
\text { different. }\end{array}$
\end{tabular}

From Table 3, although the sun- and freeze-dried kamias flower teas were not statistically different in flavor, the sundried kamias flower tea had a higher mean score. Also, from Fig. 3, the sun-dried kamias flower tea had the highest score among all the three kamiasflower tea samples in all the attributes evaluated. This served as the main basis for choosing the sun-dried kamias flower tea for comparison with conventional rose flower tea. Another reason for choosing this sample was that, if proved to contain a high antioxidant activity, then people with kamias trees can easily manufacture kamias flower tea since sun drying is a feasible and an easily available drying method even in rural areaswith no access to modern drying technologies.

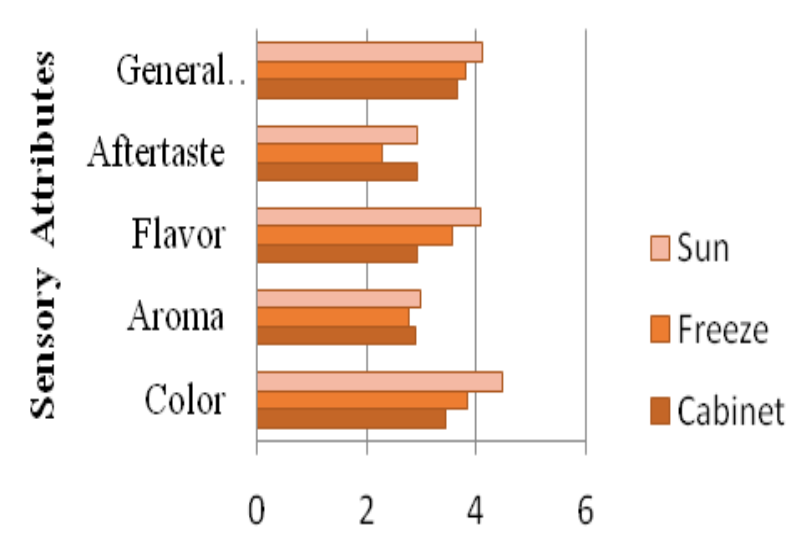

\section{Mean Score}

Fig 1: Mean scores of sensory attributes of kamias flower teas from three drying methods.

\subsubsection{Sensory Evaluation between Kamias and Rose}

\section{Flower Teas}

Quality scoring was again used in comparing the kamias and rose tea, however, the color attribute was not evaluated since their colors were not comparable. The results from this sensory evaluation were also analyzed using the same statistical treatment in the initial evaluation. Rose and kamias flower teas were significantly different in terms of their aroma, yet no statistically significant difference was observed in their flavor, aftertaste or general acceptability.

Table 4: Results of ANOVA for the attributes of kamias and rose flower teas

\begin{tabular}{|l|l|l|l|}
\hline Attribute & F-value & $\operatorname{Pr}(>\mathrm{F})$ & \\
\hline Aroma & 13.94 & 0.0010 & $\mathrm{~s}$ \\
\hline Flavor & 1.84 & 0.1879 & $\mathrm{~ns}$ \\
\hline Aftertaste & 2.30 & 0.1426 & $\mathrm{~ns}$ \\
\hline General Acceptability & 0.00 & 1.0000 & $\mathrm{~ns}$ \\
\hline *ns= not significantly different; s= significantly different \\
\hline
\end{tabular}

The aromas of the two samples were then subjected to Tukey's HSD test, and the results, in Table 5, showed that the intensity of their aroma is significantly different. Judges had found kamias flower tea to have weaker aroma than rose. However, as seen on Figure 4, both flower teas have equal mean score for general acceptability.

Table 5: Tukey's HSD test on the aroma of kamias and rose flower teas

\begin{tabular}{|l|l|l|l|l|l|}
\hline Sample & Mean & $\begin{array}{l}\text { Error } \\
\text { Mean } \\
\text { Square }\end{array}$ & $\begin{array}{l}\text { Critical } \\
\text { Value }\end{array}$ & $\begin{array}{l}\text { Test } \\
\text { Statistics }\end{array}$ & \\
\hline Rose & 5 & 2.4117 & 2.9188 & 0.9066 & $\mathrm{a}$ \\
\cline { 4 - 5 } & & & $\mathrm{b}$ \\
\hline Kamias & 3.36 & *Samples with same letter are not significantly different. \\
\hline
\end{tabular}




\subsection{Antioxidant Analyses}

Since one of the reasons to drink tea is because of the antioxidants it contains, the rose and kamias flower teas were subjected to three chemical analyses, namely, DPPH radical scavenging activity, total phenolic (TPC) and flavonoid (TFC) content determinations and reducing power assay (RPA), to assess its antioxidant activity.

Table 6: Summary of analyses on antioxidant activity of kamias and rose flower tea

\begin{tabular}{|l|l|l|l|l|}
\hline $\begin{array}{l}\text { Sampl } \\
\mathrm{e}\end{array}$ & $\begin{array}{l}\text { Total } \\
\text { Phenolic } \\
\text { Content( } \\
\text { GAE) }\end{array}$ & $\begin{array}{l}\text { Total } \\
\text { Flavonoid } \\
\text { Content } \\
(\mathrm{QE})\end{array}$ & $\begin{array}{l}\text { Reduci } \\
\text { ng } \\
\text { Power } \\
(\%)\end{array}$ & $\begin{array}{l}\text { DPPH } \\
\text { Scavengin } \\
\mathrm{g} \\
\text { Activity } \\
(\%)\end{array}$ \\
\hline $\begin{array}{l}\text { Kamia } \\
s\end{array}$ & 0.082555 & 0.245539 & $\begin{array}{l}66.758 \\
2\end{array}$ & 19.67034 \\
\hline Rose & 0.005289 & 0.038372 & $\begin{array}{l}4.5099 \\
02\end{array}$ & 51.86814 \\
\hline t-test & $\mathrm{s}$ & $\mathrm{s}$ & $\mathrm{s}$ & $\mathrm{s}$ \\
\hline
\end{tabular}

$*_{\mathrm{s}}=$ significantly different

As seen in Table 3, kamias flower tea had higher total phenolic (in galic acid equivalent) and flavonoid (in quercetin equivalent) contents, and reducing power compared to rose. However, rose flower tea had higher DPPH radical scavenging than kamias. This suggests that the kamias flower tea had antioxidants with reducing mechanisms, while rose flower tea had radical-scavenging antioxidants.

\section{SUMMARY AND CONCLUSION}

After the evaluation of sensory attributes of kamias flower teas from three drying methods, the sun-dried kamias flower tea received the highest score in all attributes compared to the cabinet- and freeze-dried kamias flower teas. The sundried kamiasflower tea was compared with rose flower tea based on their sensory properties and antioxidant activities. For the sensory evaluation, the results showed that kamias flower tea may have had weaker aroma than rose, but their general acceptability attribute had equal scores.

Chemical analyses for antioxidant activity such as DPPH radical scavenging activities, total phenolic and flavonoid contents determination, and reducing power assay, were conducted on sun-dried kamias and rose flower teas. Kamias flower tea had higher phenolic and flavonoid contents and stronger reducing power compared to rose flower tea, but rose flower tea had higher radical scavenging activity than kamias flower. This suggested that kamiasflower tea had more reducing than scavenging antioxidants. Nevertheless, both flowers were found to have antioxidant activities.

The results from sensory evaluation and chemical analyses proved that kamias flowers can be used in flower tea development since it contained antioxidants and was equally acceptable as rose flower tea.

\section{REFERENCES}

[1]. BROWN A. 2000. Understanding Food Principles and Pre.paration. USA: Wadsworth.

[2]. ANITHA R, GEETHA RV, LAKSHMI T. 2011. Averrhoa bilimbi Linn-Nature's Drug Store- A Pharmacological Review. International Journal of Drug Development \&Research. Volume 3. Issue 3.

[3]. MORTON JF. 1987. Fruits of Warm Climates. Retrieved last August 25, 2016 from https://hort.purdue.edu [4]. RAGAZZI E, VERONESE G. 1973. Quantitative Analysis of Phenolic Compounds after Thin Layer Chromatographic Separation. Journal of Chromatography A, 77 (2), 369-375.

[5]. BRAND-WILLIAMS W, CUVELIER ME, BERSET C. 1995. Use of a free radical method to evaluate antioxidant activity. LWT Food Science and Technology, 28.

[6]. RANJAN GA, GOWRI S. 2011. Anti-oxidative Potential of Probiotic Bacteria from Indian Fermented Food. International Journal of Research in Ayurveda \& Pharmacy, 2(3), 983-986.

\section{BIOGRAPHIES}

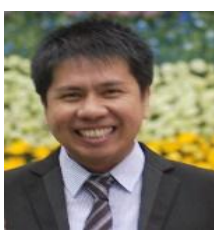

Baby Richard Navarro has an M.S degree in Agricultural Chemistry and a Ph.D. degree in Applied Biology and Chemistry from Tokyo University of Agriculture. He is now with the Institute of Food Science and Technology, University of the Philippines Los Baños.

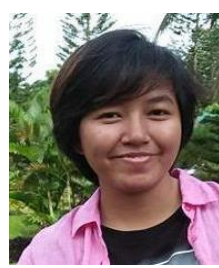

Jessamine Oña obtained her B.S. degree in Food Technology major in Food microbiology in 2017 from the University of the Philippines Los Baños. In the same year, she started working as a quality assurance specialist. 